\title{
O MOVIMENTO DA DIDÁTICA NA FORMAÇÃO DOCENTE: reverberações de nosso tempo
}

\author{
Maria Julieta Fai Serpa e Sales \\ Livia Cavalcante Vieira ${ }^{2}$ \\ Maria Marina Dias Cavalcante 3 \\ Maria Socorro Lucena Lima4
}

\section{RESUMO}

Este artigo visa a inspirar discussões acerca da didática como movimento em defesa de uma formação docente de qualidade, no rumo das necessárias mudanças que devem ocorrer para a consolidação de práticas que venham a questionar o meio e assim construir alternativas comprometidas com a dignidade do povo. Isto posto, o estudo debruçou-se sobre o seguinte questionamento: Qual o sentido da didática em nosso tempo? Para tanto, apresentou-se como objetivo refletir sobre as circunstâncias que envolvem a didática na atualidade no horizonte da formação docente. Metodologicamente, a pesquisa seguiu a abordagem qualitativa e teve como método o estudo bibliográfico. O aporte teórico baseou-se em autores como Candau (2020), Freire (2018; 2019), Marin (2018), Pimenta (2019) e Saviani (2008). Destarte, realça a necessidade de discussões permanentes sobre as práticas pedagógicas, ao considerar a didática no âmbito da concepção crítica como via de modificar o cenário atual que obstaculiza a transformação social. Palavras-chave: Didática. Formação docente. Reflexão crítica.

Palavras-chave: Didática. Formação docente. Reflexão crítica.

\footnotetext{
1 Mestranda do Programa de Pós-Graduação em Educação da Universidade Estadual do Ceará, Fortaleza, Ceará, Brasil. Especialista em Psicopedagogia clínica, institucional e hospitalar (UNICHRISTUS). Graduada em Pedagogia (UECE). Bolsista CAPES em regime de Dedicação Exclusiva. Orcid iD: https://orcid.org/0000-0002-1786-1339. E-mail: julieta.sales@aluno.vece.br

2 Mestranda do Programa de Pós-Graduação em Educação da Universidade Estadual do Ceará, Fortaleza, Ceará, Brasil. Bolsista CAPES em regime de Dedicação Exclusiva. Orcid iD: https://orcid.org/0000-0001-5381-2406. E-mail: livia-c-vieira@live.com

3 Doutora em Educação Brasileira pela Universidade Federal do Ceará. Professora do Programa de Pós-Graduação em Educação da Universidade Estadual do Ceará, Fortaleza, Ceará, Brasil. Orcid iD: https://orcid.org/0000-0003-4443-4778.E-mail: maria.marina@vece.br

4 Doutora em Educação (USP). Pós-doutorado em Educação (USP). Mestre em Educação (UFC). Graduada em Letras e em Pedagogia (URCA). Orcid iD: https://orcid.org/0000-00016600-1194. E-mail: socorro_lucena@uol.com.br
} 


\title{
THE DIDACTIC MOVEMENT IN TEACHER EDUCATION:
}

\author{
reverberations of our time
}

\begin{abstract}
This article aims to inspire discussions about didactics as a movement in defense of quality teacher education, in the direction of the necessary changes that must occur for the consolidation of practices that may question the environment and thus build alternatives committed to the sovereignty of the people. That said, the study focused on the following question: What is the meaning of didactics in our time? To this end, it was presented as an objective to reflect on the circumstances that involve didactics today in the horizon of teacher education. Methodologically, the research followed the qualitative approach, and the bibliographic study was the method. The theoretical contribution was based on authors such as Candau (2020), Freire (2018; 2019), Marin (2018), Pimenta (2019) and Saviani (2008). Thus, it highlights the need for permanent discussions on pedagogical practices, when considering didactics in the context of critical conception as a way of modifying the current scenario that hinders social transformation.
\end{abstract}

Keywords: Didactic. Teacher training. Critical reflection.

\section{EL MOVIMIENTO DIDÁCTICO EN LA FORMACIÓN DEL PROFESORADO:}

repercusiones de nuestro tiempo

\section{RESUMEN}

Este artículo tiene como objetivo inspirar discusiones sobre la didáctica como movimiento en defensa de la formación docente de calidad, en la dirección de los cambios necesarios que deben ocurrir para consolidar prácticas que cuestionen el medio ambiente y así construir alternativas comprometidas con la soberanía de los pueblos. Dicho esto, el estudio se centró en la siguiente pregunta: ¿ Cuál es el significado de la didáctica en nuestro tiempo? Para ello, se planteó como objetivo reflexionar sobre las circunstancias que envuelven a la didáctica hoy en el horizonte de la formación docente. Metodológicamente, la investigación siguió el enfoque cualitativo y el estudio bibliográfico fue el método. El aporte teórico se basó en autores como Candau (2020), Freire (2018; 2019), Marin (2018), Pimenta (2019) y Saviani (2008). Así, destaca la necesidad de discusiones permanentes sobre las prácticas pedagógicas, al considerar la didáctica en el contexto de la concepción crítica como una forma de modificar el escenario actual que dificulta la transformación social.

Palabras clave: Didáctica. Formación docente. Reflexion critica.

\section{INTRODUÇÃO}

Este ensaio propõe-se a instigar um movimento reflexivo acerca da docência como meio possibilitador de transformações sociais visando a uma educação crítica e emancipadora. Para isso, tomou-se como pressuposto 
norteador a didática e com isso discutir sobre seu estado atual como um componente da formação de professores, tendo em vista perceber os avanços e os recuos das práticas pedagógicas exercidas no âmbito da sala de aula.

É do conhecimento de todos os contínuos retrocessos que atingem a educação e a realidade das universidades que se concebem como espaços de formação por excelência. Tais retrocessos têm sua base em um modelo político neoliberal com reflexos nas escolas e, sobretudo, nas práticas pedagógicas. Compreende-se que o neoliberalismo consiste em uma política em que se prega um Estado mínimo e a prevalência das relações de iniciativa privada a reger os vínculos institucionais. No campo educacional, corrobora para a permanência de métodos que distanciam o conhecimento da reflexão e da devida interlocução com a cientificidade que serve de base para uma didática que se retroalimenta da dialogicidade (SOARES; SILVA, 2018); (NETA et al., 2020).

Cumpre realçar a essencialidade de se repensar as estratégias de ensino, bem como volver um olhar atento para os sujeitos desse processo. Dessa forma, entende-se que as concepções pedagógicas somente podem ser compreendidas se analisado o contexto em que foram planejadas, daí porque seja considerado relevante realizar um resgate histórico analisando a linha pela qual transitam as práticas educacionais. A abordagem desta pesquisa coaduna-se ao espírito crítico que pretende investigar com a devida dimensão de que é possível criar alicerces para a configuração de práticas repensadas, redimensionadas para dar conta dos desafios que se apresentam ao cenário educativo e obstaculizam o livre aprendizado.

Isto posto, cumpre destacar, o papel da didática e da percepção que se tem acerca da educação e da escola, para então trazer a discussão sobre a formação docente no sentido de amparar o profissional que se dedica à aventura de ensinar, favorecendo o germinar de olhares para as condições de vida e de trabalho dos professores, contemplando a diversidade da coletividade, ao mesmo tempo em que percebe cada um em suas singularidades. 
Em uma abordagem crítica, a pesquisa guiou-se pelo enfoque qualitativo na trajetória do método pesquisa bibliográfica. Destarte, partiu do seguinte questionamento: Qual o sentido da didática no contexto atual? Desta questão, surgiram outras, a saber: Há espaço para a reflexão da atividade docente? Como se percebe a formação docente? Como os professores constroem seu fazer didático? Que caminhos poderiam apontar a didática crítica na contemponaneidade? Nesta envergadura, elaborou-se o seguinte objetivo de estudo: refletir sobre as circunstâncias que envolvem a didática na atualidade no horizonte da formação docente.

Justifica-se a relevância de um estudo desse porte pela possibilidade de discutir acerca da interligação entre formação, didática e trabalho docente, tomando como necessário o germinar de formações continuadas com embasamento crítico, principalmente nos dias de hoje convivendo com as incertezas do amanhã, como fonte de resistência ao modelo de políticas públicas estabelecido ao longo dos anos na educação brasileira.

No que tange ao esclarecimento sobre a organização deste trabalho, importa mencionar que a estrutura contempla, após o texto introdutório, uma discussão sobre a formação docente no período atual e aborda em uma linha temporal as disposições pedagógicas, trazendo contribuições de autores como Aranha (2006), Candau (2020), Freire (2018; 2019), Marin (2018), Pimenta (2019) e Saviani (2008).

\section{METODOLOGIA}

O percurso metodológico tem como norte a abordagem qualitativa por tratar-se de um estudo no campo das ciências sociais, aqui no caso, a educação, e por lidar com as subjetividades humanas, respondendo a questões singulares, aprofundando-se nos fenômenos com os quais se depara na jornada investigativa de forma coerente e contextualizada (MINAYO, 2019).

Para dar sentido ao objeto de análise optou-se pelo método da pesquisa bibliográfica, por ter sido elencado um acervo de livros, artigos científicos, periódicos e outras fontes já escritas e publicadas para fortalecer 
a produção de conhecimento, colocando os pesquisadores em contato direto com as informações, em fluida interlocução, com a liberdade de trazer um repensar sobre a temática em questão (CAVALCANTE; SILVA, 2011).

Mesmo diante da infinidade de fontes já escritas, cumpre salientar o compromisso ético do estudo com o rigor no levantamento e na interpretação dos dados colhidos, reconhecendo que a pesquisa fortalecese com o reconhecimento de que estamos em perene aprendizagem, com uma constante abertura para ressignificar as percepções e os resultados das análises, entendendo a necessidade do movimento de idas e vindas, próprio da seara científica.

\section{RESULTADOS E DISCUSSÃO}

Inicialmente, vale destacar que a discussão foi planejada para colocar em evidência as principais características das tendências pedagógicas que perpassam a historiografia da educação brasileira. Mesmo porque parte-se do pressuposto de que há uma necessidade humana em compreender as particularidades dos contextos, entendendo que a memória constitui um arsenal privilegiado para interpretar e conhecer os fenômenos (MAGALHÃES JUNIOR, 2007).

Segundo Magalhães Junior (2007, p. 54), "[...] somos atores que vivem cada ato com cenários e contextos determinados. Não podemos nos entender fora de delimitações temporais, impregnadas de suas

particularidades [...]". Aranha (2006) corrobora com este pensamento e anuncia que os humanos são seres históricos, ressaltando que o passado é essencial pois é a partir dele que entendemos o presente.

O mundo e suas particularidades resultam desse movimento que entrelaça o passado e o presente arquitetando o futuro. No que diz respeito à educação e ao campo específico da formação docente, objeto desse estudo, neste vínculo encontra-se a raiz para a compreensão dos fatores que reconhecidamente obstaculizam a aprendizagem significativa e a 
garantia de um ensino emancipatório (FREIRE, 2018). Junges, Ketzer e Oliveira (2018, p. 89) reforçam esse pensamento e acrescentam:

\begin{abstract}
Algumas dificuldades no que tange ao trabalho docente já são históricas, como a precarização das estruturas físicas, crises éticas e sociais, remuneração nem sempre adequada etc. Talvez, no entanto, um dos maiores desafios esteja relacionado à formação, ou seja, à constituição de um professor que ajude na melhoria da construção social e cidadã, contribuindo com o atual momento histórico-cultural.
\end{abstract}

Desta forma, propõe-se um diálogo entre os autores que sustentam o grupo teórico deste estudo, seguindo uma linha temporal contemplando as tendências e o contexto de ensino-aprendizagem desde o período colonial até os tempos atuais, em uma abordagem crítica.

O intuito deste estudo contempla também enaltecer pontos relevantes da trajetória do ensino no Brasil por meio de uma conversa entre dez autores que vêm trazer contribuições aos profissionais que atuam nas escolas, ao ambiente universitário, como também para a sociedade para que possa compreender a temática que envolve didática e formação docente em sua inteireza. Conta-se, portanto, com a concepção de Aranha (2006), Candau (2020), Franco (2012), Freire (2018; 2019), Marin (2018), Pimenta (2019) e Saviani (2008) para o desenvolvimento de uma compreensão sobre o objeto em estudo - a didática e seu legado para a docência -, compreendendo como necessária a atitude de insurgência tendo em vista os retrocessos por que passa a educação brasileira nos últimos tempos, para a ressignificação de si, dos pares e do meio educacional (CANDAU, 2020).

Consoante Silva, Sales e Cavalcante (2020, p. 3) o contexto atual enquadra-se na seguinte narrativa:

Vivenciamos no Brasil, ao longo dos últimos tempos, um momento singular em que assistimos à transição de sucessivos governos presidenciais de esquerda para gestões que aproximam-se da tendência ultra-direitista neoliberal. Os dois últimos governos em exercício - de Agosto de 2016 a aneiro de 2018 e de Janeiro de 2019 até o presente momento inauguraram os primeiros mandatos presidenciais de linha 
conservadora após um período de 13 anos. Nesta conjuntura de mudanças observamos o germinar de uma cultura do ódio que introduziu em nosso meio uma polarização cujos reflexos alcançaram muitos setores -economia, cultura, saúde, inclusive a educação -com discursos e ações que fizeram brotar a semente da discórdia na sociedade civil.

Isto posto, uma vez que a educação situa-se no espaço-tempo desta complexa conjuntura elucidada acima, projeta-se que se ampliem os esforços em busca de alternativas para a superação deste quadro tendo em vista que a educação é fundamental quando se imagina um projeto de emancipação humana.

Assim, o leitor depara-se com um texto simples e intenso, seguindo o rigor de um trabalho feito com o método científico, mas sem perder de vista a leveza na apreciação de sua mensagem para a tão sonhada mudança que possa reacender a chama da esperança por dias melhores.

Consoante Saviani (2008), por longo tempo a educação brasileira foi monitorada pelos colonizadores jesuítas numa perspectiva tradicional, cuja concepção fundamentava-se na ideia da transmissão de conteúdo, em que o discente era compreendido como um receptor. Desse modo, o professor poderia despejar seus conteúdos, configurando o que Freire (2018) intitulava "concepção bancária" do ensino, colocando em questionamento qual seria - papel da didática, apontando para lacunas no que diz respeito à ausência de reflexões.

Logo, o objetivo do colonizador era aculturar. Para Bosi (1992, p. 17), "[...] aculturar um povo se traduziria, afinal, em sujeitá-lo ou, no melhor dos casos, adaptá-lo [...]". Ou seja, a finalidade do projeto colonizador consistia no domínio em busca de submissão; colonizando mentes, ocupando o território forasteiro. De acordo com Stascxak et al. (2020), esta realidade imperou em solo brasileiro por cerca de 210 anos, de 1549 a 1759.

No cenário descrito acima, evidencia-se que a criticidade tem espaço bastante limitado, percebendo a escola como lócus de notável postura segregacionista e legitimador de relações verticalizadas entre os seres que fazem parte do cotidiano de sala de aula, a saber, professores e estudantes 
(FREIRE, 2018). As ações realizadas em um espaço como esse configuram uma didática que segue métodos expositivos sem preocupar-se com a emancipação dos indivíduos tampouco com a coerência de atitudes comprometidas com a dimensão crítica (PIMENTA, 2019).

Avançando um pouco mais no tempo, vem o período das reformas pombalinas e a instituição das aulas régias - século XVIII -, com a continuidade do domínio religioso (SAVIANI, 2008). Entretanto, não houve grandes mudanças no sentido de superar o aspecto do ensino tradicional. Acerca do período em que atuou Marquês de Pombal, Aranha (2006, p. 216) traz o seguinte relato:

\begin{abstract}
Através Pombal instituiu as aulas régias ("régias" porque pertenciam ao rei, ao Estado e não à Igreja). Começou estruturando os chamados Estudos Menores, que correspondiam ao ensino fundamental e médio (primeiras letras e ensino de humanidades). Em 1772 foi iniciada a segunda fase, com a Reforma dos Estudos Maiores, quando se reestruturou a Universidade de Coimbra. Afastada a Companhia de Jesus, assumiu a Ordem do Oratório - a qual já tinha recebido proteção do rei em 1740 —, que era conhecida pela visão mais avançada, aberta às ideias iluministas.
\end{abstract}

$\mathrm{Na}$ verdade, essa cultura de precariedade da educação - que se reverbera na didática e na formação docente - vai estender-se até o momento atual, com o contínuo desmonte de direitos adquiridos, falta de investimentos em larga escala e a criação de um ambiente hostil à universidade e à ciência, como parte do plano de desconstrução do conhecimento de acordo com o corolário neoliberal da extrema direita. 0 cenário descrito carece de um olhar crítico para a concretização de uma didática voltada para a empatia e para o resgate da dignidade popular, conclamando a resistência (CANDAU, 2020).

De acordo com Saviani (2008), no século XIX, na senda de movimentos como o lluminismo, o ensino tradicional permanecia enraizado na sociedade, uma vez que imperava a monarquia absolutista com a imposição de leis de forma hierarquizada com a continuidade da distinção 
de classes e privilégios. Portanto, teve continuidade o paradigma de colonização, não restando uma alternativa à ampla população a não ser adaptar-se. Isso significava um sistema para reforçar a coerção social através do ensino, sem levar em consideração as peculiaridades do meio.

Sobre a reforma pombalina, Gondra e Schueler (2008, p. 22) afirmam: "[...] A reforma pombalina consistiu numa tentativa de criar um sistema de ensino capaz de unir portugueses e europeus sob paradigmas da llustração, reinterpretados e apropriados conforme o modelo de Estado absolutista, estamental e hierárquico [...]". Ou seja, ainda não havia constituído-se um sistema educacional com identidade própria, tampouco para uma didática que pudesse promover uma transformação no sentido de dar visibilidade aos oprimidos.

Até então havia forte influência da corrente positivista. Chegando ao século XX, vem a tendência liberal renovada-Pedagogia Nova--, que surgiu no Brasil dos anos vinte, o Ciclo de Reformas Estaduais impulsionado por intelectuais como Lourenço Filho, Anísio Teixeira, Fernando de Azevedo e Francisco Campos. Surgiu o movimento escolanovista com o intuito de construir uma educação que refutasse a abordagem tradicional e centrasse seu olhar para os estudantes, com especial atenção à sua formação. Por essa razão, tal movimento era contrário ao autoritarismo e à ideia de passividade, uma vez que buscava possibilidades de desenvolver a autonomia discente e o estímulo à sua socialização (ARANHA, 2006).

E aqui está representada a tendência renovada progressivista, partindo da ideia de que cabe à instituição escolar otimizar a integração direta dos discentes com o mundo. Dessa forma, os aprendentes poderiam buscar o conhecimento e aplicá-los em situações do cotidiano. O arcabouço de Dewey (norte-americano) serviu bem a este propósito, sobretudo entre o período de 1920 a 1940 (ARANHA, 2006).

Tal conjuntura poder-se-ia considerar um avanço para o campo da didática e da docência. Contudo, cumpre salientar que, de acordo com Aranha (2006), a excessiva centralidade no educando provocou críticas ao modelo escolanovista, por esvaziar de sentido o ensinar, tarefa docente. 
Não que o professor fosse o detentor exclusivo do aprender e que centralizasse o processo, mas não se pode negar a importância de todos os atores na condução do aprendizado, principalmente dos profissionais do magistério.

Seguiu-se com uma postura considerada contraditória até mesmo por conta da tentativa de manter os privilégios da burguesia, de acordo com as conveniências de quem está no poder (ARANHA, 2006). Ainda que tenha havido esforços no sentido de superar a perspectiva tradicional, a simbiose entre poder, educação e religião continuou a ser o mote do jogo de interesses que permeou a constituição do sistema político, econômico e social, sobretudo os processos de ensino, reduzindo a formação de professores a um preparo sem o devido estímulo ao questionamento, de tal modo que se pergunta como esses profissionais iriam superar o currículo oculto e propiciar aos estudantes um ambiente favorável a reflexões e como seria a didática nesse prisma (PIMENTA, 2019).

Ainda de acordo com Saviani (2008), a Escola Nova aperfeiçoou o ensino em busca de melhor qualidade para as elites. Acerca deste período, Stascxak et al. (2020, p. 4) faz a seguinte análise:

Vale destacar que esses paradigmas de escolas tradicionais eram inspirados nos padrões da sociedade burguesa como forma de manter e consolidar a democracia que atenderia a esses interesses. [...] A escola é erigida, pois, no grande instrumento para converter os súditos em cidadãos [...].

Ou seja, as fragilidades que marcaram o processo de elaboração da educação brasileira constituíram uma identidade de precarização. Em que pese a onda otimista impulsionada pelo escolanovismo e a proposta de ressignificação das práticas pedagógicas, minimizou a importância dos professores, esvaziando de sentido a sua atuação, bem como descuidando da parte conteudista que também é relevante na construção de uma didática transformadora (ARANHA, 2006).

Cabe mencionar, segundo Stascxak et al. (2020, p. 8), no que diz respeito à formação docente, que em 1939 houve a primeira 
regulamentação do curso em nível superior de Pedagogia. Assim as autoras descrevem:

O Curso de Pedagogia teve sua primeira regulamentação em 1939 no contexto da Ditadura Vargas, ano em que foi organizada a Faculdade Nacional de Filosofia e a Universidade do Brasil, cuja regulamentação se deu mediante o Decreto-Lei n. 1.190, elaborado no dia 4 de abril. Esse decreto, na verdade, objetivou estabelecer uma espécie de parâmetro (era o chamado padrão federal) ao qual o currículo do Curso de Pedagogia deveria se equiparar, o que reduziu a atividade pedagógica ao uso e à prática [...]. Esse esquema de formação se consolidou e se estendeu para todo o país.

Importante registrar que não havia uma articulação clara entre o curso de Pedagogia e o campo de atuação do pedagogo, porém pode-se perceber esta primeira regulamentação como uma tentativa de abrir espaço para discussão sobre a profissão do magistério, inaugurando uma nova era na formação docente.

Com a crise do escolanovismo, abriu-se espaço para a tendência liberal tecnicista, a qual emergiu em solo brasileiro no período conhecido como Ditadura Militar - a partir do golpe que depôs o então presidente João Goulart -, momento a partir do qual houve mudanças com a imposição de um regime com duras e severas punições à pluralidade de ideias e concepções, principalmente àquelas que destoassem do padrão inquestionável. As forças conservadoras agiram com o pretexto de impedir que o Brasil viesse a tornar-se Cuba, bem como no combate ao comunismo (ARANHA, 2006).

No que tange à educação, veio o tecnicismo com sua torrente de retrocessos para grande parte da população, contribuindo com ações de cunho ideológico para o aumento das desigualdades já existentes e o silenciamento das manifestações em contradição com o regime imposto (SAVIANI, 2008). A ideologia criada pela aliança político-militar fundamentou o modelo tecnicista, bem como tratou de justificar a censura e as perseguições, assim como os lamentáveis episódios de prisões, exílios, torturas 
e assassinatos. Nesse plano de manipulação da verdade, considera-se que a educação foi utilizada como um dos principais veículos, com planos e diretrizes elaborados para controlar, adaptar, apassivar (ARANHA, 2006).

No âmbito educacional, a referida conjuntura implicava em vigiar a postura dos professores, de modo que esses profissionais sequer poderiam questionar o currículo e as ações vivenciadas na escola ou refletir sobre as aulas. Houve censura dos conteúdos, bem como do material didático. Nessa direção, a didática passou a ser radical, mitificando os interesses que havia por trás de um currículo que destoava da concepção dialógica para uma formação de cunho crítico, por uma pedagogia libertadora, motivo pelo qual um dos objetivos da época tenha sido oferecer resistência ao pensar autêntico (FREIRE, 2019). Para Candau (2020, p. 23),

\begin{abstract}
Neste contexto, a Didática é concebida como estratégia para o alcance dos "produtos" previstos para o processo de ensinoaprendizagem. Enfatiza-se a importância de objetivos instrucionais formulados com caráter comportamental que possam ser claramente medidos, assim como a construção das sequências de ensino elaboradas de modo preciso, dos instrumentos de avaliação, das diferentes técnicas e recursos didáticos. O centro das preocupações é a produtividade, eficiência, racionalização, operacionalização e controle.
\end{abstract}

O enfoque na produtividade reverbera-se em todas as instâncias da instituição escolar, o que significa elencar a formação docente, os vínculos entre os indivíduos, o planejamento, a metodologia e a avaliação, orientando o ensino para um acúmulo de informações e de busca por rendimentos e eficiência, sem necessariamente primar pela qualidade do estudo e para as singularidades dos estudantes e da escola. A partir deste ângulo, entende-se que a didática é interpretada como técnica ou instrumento, distanciando-se, pois, da criticidade e seu corolário de possibilidades para a integração entre os humanos e o conhecimento (CANDAU, 2020).

Consoante Marin (2018, p. 22-23), "foi contra esse estado de coisas que transcorreram várias ações e toda movimentação de diversos segmentos 
[...]". Ou seja, em que pese o cenário de tensões, houve planos e ações no sentido de transgredir tal status quo a partir de movimentos populares com crescente participação de camponeses, operários e estudantes (ARANHA, 2006).

Durante os anos 50 e 60, emergiv a Pedagogia Libertadora com Paulo Freire, cujos escritos foram censurados devido ao seu conteúdo, para a época, ser demasiado crítico, pelo fato de colocar os humanos como sujeitos da história; sujeitos que pensam e que são protagonistas, o que incomodou de modo veemente os militares. Daí o motivo por que Freire foi exilado durante dezesseis anos (1964-1980), e este teórico tenha adquirido notoriedade somente na década de 1980, com o enfraquecimento do regime militar - e em 1985 o seu término.

Consoante Candau (2020, p. 24), "a década de 1980 foi, sem dúvida, de especial relevância para o desenvolvimento da Didática. Multiplicam-se as produções acadêmicas, os seminários, congressos e palestras, as buscas pela construção de uma Didática na perspectiva crítica". Esse raciocínio relaciona-se à percepção da didática como meio de pensar acerca das práticas pedagógicas, do meio e dos estudantes a quem a educação destina-se, bem como inclui a empatia e a emergência de criar possibilidades para uma militância que estimule a todos a perceberem as contradições da realidade.

E aqui registra-se a importância de Freire como um marco na educação brasileira. Franco (2012, p. 68) ressalta que "por meio de uma prática mediada pelo diálogo e pela valorização da cultura do aluno, Paulo Freire vê na educação uma forma política de transformar a sociedade, para que esta se torne mais justa e mais solidária". Portanto, presume-se que esta perspectiva é revolucionária por elencar medidas democráticas, anunciando uma didática cuja essência reside na partilha e no intercâmbio de saberes.

Sustenta-se a formação docente como um espaço privilegiado de amplitude das reflexões, configurando-se em horizonte para a afirmação de uma educação democrática e humanizadora, transcendendo o 
cumprimento de metas conteudistas ao envolver-se com o coletivo, olhando para as especificidades dos educandos e reconhecendo como fundamental o compromisso com a construção de aprendizagens sólidas e significativas. A formação nesses moldes caracteriza-se na condição de eixo possibilitador de transformações. Nessa toada, Dias e Ferreira (2017, p. 395) apostam no desenvolvimento profissional de professores e complementam:

Com relação ao significado da palavra "desenvolvimento", encontramos na origem de "desenvolver", como "des + envolver", ou seja, a retirada de um en-vólucro. Isso poderia ser entendido como mudança. Então, desenvolvimento profissional pode significar uma mudança no professor.

Mudança esta que significa para o paradigma atual o desabrochar de renovadas atitudes que inclusive podem ser encontradas no legado freireano, bem como nos autores que aqui sustentam o estudo e seguem sua linha de avaliação histórica da significância da conjuntura.

Além disso, Freire criou possibilidades de reconfigurar os espaços e as relações entre os atores que convivem no ambiente educacional, para a construção de uma atmosfera humanizante e humanizadora (FREIRE, 2019). Franco (2012, p. 70-71) aponta para a importância do legado freireano e da construção de uma pedagogia com alicerce na autonomia do pensar:

[...] a Pedagogia pode ainda auxiliar na reconstrução do processo civilizatório por meio de uma pedagogia do sujeito, a qual 0 ensine para a liberdade e para a autonomia, preocupada com os valores que possibilitam a vivência em comum, entre os quais a solidariedade e a diversidade. Mais do que qualquer coisa, no entanto, essa pedagogia precisa educar para romper a dissociação, a falta de comunicação, entre cultura e economia, entre afeto e tecnologia, entre necessidade e desejo. Novamente precisamos de uma pedagogia que seja tecida com o outro, na perspectiva da dignidade humana [...].

Isto posto, na ótica de Aranha (2006), esse estado de convite à reflexão contribuiu para o reconhecimento da necessidade de existirem vínculos pautados na dialogicidade entre professores e alunos. Uma relação 
sustentada na abordagem crítica movida pela ciranda dialética que mobiliza todos a repensarem suas ideias e atitudes. Conforme Marin (2018, p. 33), a mencionada postura fortalece a didática e situa a formação docente em um paradigma revolucionário, pois para ela "[...] boa parte do que ocorreu esteve orientado por uma epistemologia pouco crítica e nada dialética, em que as relações ocorreram de modo reprodutivo e funcional [...]", ou seja, sem a devida conscientização, com a construção de relações humanas enraizadas no espírito de solidariedade, vislumbrando indivíduos criativos e criadores (ARANHA, 2006).

Seguidamente, no final da década de 1970, vem a tendência progressista crítico-social dos conteúdos e sua postura inovadora ao associar a instituição escolar à transformação, reconhecendo a existência de uma multiplicidade de fatos sociais em seu interior. Condição favorável para assumir que a escola tem caráter formativo concebendo a atividade docente como mediação, em regime de parceria colaborativa por interligar os estudantes ao conhecimento (ARANHA, 2006).

Cezar (2020, p. 1249) aproxima-se desse argumento ao preocupar-se com a questão do saber oriundo do vínculo entre os seres da educação escolarizada. Adepto da corrente freireana que aposta na essencialidade da dialogicidade como pressuposto básico para o movimento de construção do aprendizado mútuo, enfatiza: "[...] Enquanto seres inacabados, somos inconclusos, e essa inconclusão implica a inserção do sujeito inacabado num constante processo social de busca". Ou seja, o aprendizado fortalece-se com a possibilidade dos espaços humanizantes, estes, por sua vez, materializados pelo reconhecimento da partilha como eixo fundante da educação e da vida.

Um aprendizado que se constitui quando se adquire o devido amadurecimento do senso crítico, para o qual inclinam-se as tentativas de discussão sobre o ensino como vertente de harmonia com a percepção contínua das limitações inerentes aos humanos justamente por meio da escuta, uma escuta que medita e legitima a pesquisa como razão de ser da prática pedagógica. Além disso, essa postura contribui para a construção 
de um pacto coletivo de emancipação mútua. Destarte, Pimenta (2019, p. 30) evidencia:

Nesse sentido, a educação se caracteriza como processo de formação das qualidades humanas, enquanto o ensino, objeto da didática, é o processo de organização e viabilização da atividade de aprendizagem em contextos específicos para esse fim. Em síntese, a pedagogia é a teoria e a prática da educação, e a didática, o campo da pedagogia que trata do ensino [...].

Percebe-se nesta fala que há uma tendência que aponta para uma didática que tem sua razão emancipadora, de modo que a pedagogia histórico-crítica propõe-se a rever o papel dos métodos e estratégias de ensino, objetivando modificar o cenário de recorrente insucesso escolar, partindo em busca de um ensino justo e democrático, e assim formar para além de meramente preparar; formar criticamente para mudar e não mais adaptar, atentando, pois, para a ressignificação da parte conteudista e das ações pedagógicas, além das próprias relações humanas (ARANHA, 2006).

Numa abordagem crítica, "[...] o educador deve ajudar os alunos a questionar sua realidade, problematizá-la e tornar visível o que antes estava oculto, desenvolvendo novos conhecimentos sobre ela" (PIMENTA, 2019, p. 36). Candau (2020, p. 29) corrobora com este entendimento e salienta:

[...] Parto da afirmação da ancoragem histórico-social dos diferentes conhecimentos e de seu caráter dinâmico, o que supõe analisar suas raízes históricas e o desenvolvimento que foram sofrendo, sempre em íntima relação com os contextos nos quais este processo se vai dando e os mecanismos de poder nele presentes. Considero importante reconhecer a existência de diversos conhecimentos no cotidiano escolar e procurar estimular o diálogo entre eles, assumindo os conflitos que emergem desta interação.

Nesta direção, assume-se o compromisso com uma educação que possui como objetivo oportunizar circunstâncias de aprendizado entre todos os que fazem parte do contexto escolar, de modo que a realidade seja a eles desvelada através do conhecimento. Uma educação que perpasse a 
compreensão das subjetividades do outro, primando pela escuta, que nasce da humanização. Freire (2019, p. 57) amplia este pensamento e fala acerca de uma cultura educacional para o enfrentamento da ideologia dominante:

Em qualquer destes momentos, será sempre a ação profunda, através da qual se enfrentará, culturalmente, a cultura da dominação. No primeiro momento, por meio da mudança da percepção do mundo opressor por parte dos oprimidos; no segundo, pela expulsão dos mitos criados e desenvolvidos na estrutura opressora e que se preservam como espectros míticos, na estrutura nova que surge da transformação revolucionária.

Outrossim, esta cultura parte de iniciativas que visem a promover a soberania do povo, uma vez que guarde a clareza de que a partir da educação como base de viabilizar a justiça social e a didática como meio de garantir uma pedagogia que reflita sobre as especificidades do meio, acolhendo os humanos e suas particularidades.

Nesse sentido faz-se importante discutir formas de impulsionar o movimento de conscientização e reorientação do sentido da didática hoje a partir de um olhar que favoreça o despertar do senso crítico e do espírito filosófico, na contramão do tecnicismo que tenta retornar na atualidade.

Qual o sentido da docência no contexto atual? No entendimento de Candau (2020, p. 30-31), há que se buscar mecanismos para descolonizar o saber, construindo alternativas de superação das dificuldades que encaminham o saber por uma trilha de violência e desigualdades, e assim a autora defende:

Estamos urgidos, mais do que nunca, a afirmar a democracia, uma democracia plena, que reconheça os diversos sujeitos individuais e coletivos. A apoiar os movimentos sociais que lutam nesta perspectiva, enfatizando a afirmação de uma educação comprometida com a justiça, o reconhecimento dos diferentes grupos socioculturais presentes na nossa sociedade, pautada numa perspectiva transformadora, multidimensional e plural, orientada à formação de cidadãos e cidadãs, sujeitos de direito, protagonistas, individual e coletivamente da construção social. Somente coletivamente podemos construir uma nova perspectiva [...]. 
A didática, portanto, afirma-se como caminho reflexivo e propulsor de abordagens críticas capazes de propiciarem o encontro da docência com a práxis, motivo pelo qual advoga-se que as discussões acerca desta temática aproximam a educação da ciranda reflexiva que por sua vez compreende a formação docente pautada neste processo como uma importante aliada na construção de um ambiente emancipatório, de mãos dadas com o espírito de insurgência.

\section{CONSIDERAÇÕES FINAIS}

Retomando o objetivo deste ensaio o qual busca refletir sobre as circunstâncias que envolvem a didática na atualidade no horizonte da formação docente, compreende-se a necessidade de haver uma ampla conscientização no sentido de resgatar a participação popular nos processos que fazem parte de seu meio, principalmente a educação, uma vez compreendida como condição de busca pela soberania do povo. Os contínuos retrocessos que avançam de modo contundente e excludente apontam para a necessidade de construir novas respostas.

O olhar para a história invoca a memória e amplia a linha de compreensão sobre as características da educação no contexto atual, sobretudo no que tange ao reconhecimento dos limites e possibilidades do ensino, evidenciando as lacunas da formação docente a qual não se restringe ao âmbito universitário, mas consolida-se continuamente no labor diário, no chão da escola. De acordo com as discussões realizadas neste trabalho, a partir do trabalho docente reúnem-se as condições para a ressignificação da prática pedagógica, irmanada com a conscientização.

A formação docente que se configura pela abordagem crítica contribui para que o alicerce da didática tenha como foco a partilha, a escuta e o olhar sensível às singularidades do meio e do contexto, o que envolve um constante repensar acerca das ações concretizadas em sala de aula, em especial sobre a importância do social. Em que pese a expressiva quantidade de escritos acerca da didática e da formação docente, 
cumpre registrar a necessidade de haver constantes discussões sobre esta temática, pela emergência da conjuntura neoliberal. Destarte, considera-se a imprescindibilidade de se compreender a didática como um movimento historicamente datado e situado no bojo de uma concepção crítica como via de modificar o cenário atual que obstaculiza a transformação social. De mãos dadas com a resistência.

\section{REFERÊNCIAS}

ARANHA, M. L. de A. História da educação e da pedagogia: geral e Brasil. 3 ed. São Paulo: Moderna, 2006.

BOSI, A. Colônia, culto e cultura. In: BOSI, Alfredo. Dialética da colonização. São Paulo: Companhia das Letras, 1992. p. 11-64.

CANDAU, V. M. Didática: revisitando uma trajetória. In: CANDAU, V. M.; CRUZ, G. B. da; FERNANDES, C. (Org.). Didática e fazeres-saberes pedagógicos: diálogos, insurgências e políticas. Petrópolis: Vozes, 2020. p. 22-32.

CAVALCANTE, M. M. D.; SILVA, S. P. Conhecimento, método e pesquisa bibliográfica: reflexões epistemológicas e metodológicas. In: NÓBREGATHERRIEN, S. M.; FARIAS, I. M. S. de; NUNES, J. B. C. (Orgs.). Pesquisa científica para iniciantes: caminhando no labirinto. Fortaleza: EdUECE, 2011.

CEZAR, M. dos S. Saberes em relações dialógicas: "não há saber mais ou saber menos, há saberes diferentes". Pesquisa e Debate em Educação, Juiz de Fora, v. 10, n. 2, p. 1247-1258, 2020. Disponível em:

https://periodicos.ufjf.br/index.php/RPDE/article/view/31509. Acesso em: 08 mar. 2021.

DIAS, L. F.; FERREIRA, M. Políticas de formação continuada de professores e desenvolvimento profissional. Pesquisa e Debate em Educação, Juiz de Fora, v. 7, n. 2, p. 391-411, 2017. Disponível em:

https://periodicos.ufjf.br/index.php/RPDE/article/view/31643. Acesso em: 08 mar. 2021.

FREIRE, P. Pedagogia do oprimido. 71 ed. Rio de Janeiro/São Paulo: Paz e Terra, 2019.

FREIRE, P. Pedagogia da autonomia: Saberes necessários à prática educativa. 57 ed. São Paulo: Paz e Terra, 2018.

FRANCO, M. A. do R. Pedagogia e prática docente. São Paulo: Cortez, 2012. 
GONDRA, J. G.; SCHUELER, A. Educação, poder e sociedade no Império brasileiro. São Paulo: Cortez, 2008.

JUNGES, F. C.; KETZER, C. M.; OLIVEIRA, V. M. A. de. Formação continuada de professores: saberes ressignificados e práticas docentes transformadas.

Educação \& Formação, Fortaleza, v.3, n.9, p. 88-101, 2018. Disponível em: https://revistas.uece.br/index.php/redufor/article/view/858. Acesso em: 08 mar. 2021.

MARIN, A. J. A didática, as práticas de ensino e alguns princípios para a pesquisa e a docência. In: MARIN, A. J.; PIMENTA, S. G. (Orgs.). Didática: teoria e pesquisa [recurso eletrônico]. 2 ed. Araraquara: Junqueira\&Marin: Ceará: UECE, 2018. Disponível em: https://docero.com.br/doc/n00xns1 . Acesso em: 05 fev. 2021.

MINAYO, M. C. de S. O desafio da pesquisa social. In: MINAYO, M. C. de S.; DESLANDES, S. F.; GOMES, R. Pesquisa social: teoria, método e criatividade. 2 ed. Petrópolis: Vozes, 2019.

NETA, A. A. de C.; MOURA, J. da S.; CARDOSO, B. L. C.; NUNES, C. P. contextos da precarização docente na educação brasileira. Revista Exitus, Santarém, v. 10, p. 1-25, 2020. Disponível em:

http://www.ufopa.edu.br/portaldeperiodicos/index.php/revistaexitus/article/ view/1261. Acesso em: 11 mar. 2021.

PIMENTA, S. G. As ondas críticas da didática em movimento: resistência ao tecnicismo/neotecnicismo neoliberal. In: SILVA, M.; ORLANDO, C.; ZEN, G. (Orgs.). Didática: abordagens teóricas contemporâneas. Salvador: EDUFBA, 2019. p. 19-64.

SAVIANI, D. História das ideias pedagógicas no Brasil. 2 ed. rev. e ampl. Campinas: Autores associados, 2008.

SILVA, J. P. G. da; SALES, M. J. F. S. e; CAVALCANTE, M. M. D. O alinhamento do pensamento freireano com o ser humano: análise de frequência de palavras do livro Pedagogia da Autonomia. Revista Exitus, Santarém, v. 10, p. 01-31, 2020. Disponível em:

http://www.ufopa.edu.br/portaldeperiodicos/index.php/revistaexitus/article/ view/1500. Acesso em: 10 mar. 2021.

SOARES, G. L.; SILVA, J. F. A influência do neoliberalismo na educação: reflexo na formação docente. Revista Professare, Caçador, v.7, n.1, p. 26-40, 2018. Disponível em:

https://periodicos.uniarp.edu.br/index.php/professare/article/view/1531. Acesso em: 06 mar. 2021. 
STASCXAK, F. M.; SALES, M. J. F. S. e; COSTA, C. C. da; BARBOSA, T. C. L.

Vicissitudes da formação de professores no Brasil. In: Congresso Internacional de Ensino e Formação Docente (CIEF) 1., 2020, Redenção. Anais [...] Redenção: UNILAB, 2020. p. 1-12. Disponível em:

https://www.even3.com.br/anais/cief2020/. Acesso em: 30 jan. 2021.

Recebido em: 23.12.2020

Aprovado em: 15.03.2021

Publicado em: 19.03.2021 